\title{
Einladung zur Mitgliederversammlung der DRG am Mittwoch, dem 20. Mai 2020
}

Zur ordentlichen Mitgliederversammlung der Deutschen Röntgengesellschaft - Gesellschaft für Medizinische Radiologie e. V. (DRG) am Mittwoch, dem 20. Mai 2020, von 18:00-19:15 Uhr im Congress Centrum Leipzig (CCL) im Raum Röntgen, lädt der Vorstand der DRG die Mitglieder der DRG hiermit herzlich ein.

\section{Tagesordnung}

TOP 1: Begrüßung

TOP 2:Totengedenken

TOP 3: Genehmigung des Protokolls der
Mitgliederversammlung vom 31. Mai 2019 (veröffentlicht im Jahresbericht 68, Januar 2020)

TOP 4: Bericht des Präsidenten

TOP 5: Bericht des Schatzmeisters

TOP 6: Bericht der Kassenprüfer

TOP 7: Entlastung des Vorstands

TOP 8: Vorschläge für Ehrungen 2021

TOP 9: Wahl der Kassenprüfer 2021

TOP 10: Wahl des Kongresspräsidenten 2023

TOP 11: Ergebnisse der zweiten bundesweiten Weiterbildungsumfrage des Forums Junge Radiologie
TOP 12: Einladung zum Röntgenkongress 2021

TOP 13. Verschiedenes

Die Einlasskontrolle erfolgt über den Kongressausweis. Entsprechend der Satzung der DRG können an der Mitgliederversammlung nur Mitglieder teilnehmen, deren Beitragskonto für 2020 ausgeglichen ist.

Im Namen des Vorstands Prof. Dr. Gerald Antoch (Präsident) 